\title{
Utilization of waste lignin to prepare controlled-slow release urea
}

\author{
Jamshid Behin $^{1} \cdot$ Nader Sadeghi $^{1}$
}

Received: 28 June 2016/Accepted: 21 September 2016/Published online: 30 September 2016

(C) The Author(s) 2016. This article is published with open access at Springerlink.com

\begin{abstract}
Purpose The present work reports an economically attractive improvement in the area of producing particulate slow release nitrogen fertilizer using lignin as a waste effluent of pulp and paper manufacturing process.

Methods An improved coating of modified lignin was applied on the surfaces of the individual urea particles. The Kraft and Sulfite black liquors obtained from two different paper pulping units and were used as sources of sulfate and sulfite lignin, respectively. Chemical modification of extracted lignin was performed through acetylation reaction by acetic acid/sodium metabisulfite to increase its hydrophobicity character. In a separate experiment, a thin layer of synthesized acetylated lignin was coated on granular urea by fluidized-bed technique. The nitrogen release of synthesized fertilizer in the water and soil was examined by the Kjeldahl method.

Results The analysis of FTIR spectra indicated the changes in the functional groups of acetylated lignin. Petrographic photography and scanning electron microscopy (SEM) analyses demonstrated a uniform and homogeneous covering of the urea surface. The 7 day nitrogen release rate of urea coated by acetylated lignin in soil was obtained 36.3 and $45.3 \%$ for Kraft and Sulfite lignin, respectively, whereas this value was $59 \%$ for sulfur coated urea.

Conclusions Using industrial wastewater as source of lignin gives satisfactory results for industrial applications and yields a quality green fertilizer product with reduced
\end{abstract}

Jamshid Behin

Behin@razi.ac.ir

1 Department of Chemical Engineering, Faculty of Engineering, Razi University, Baghe Abrisham, Kermanshah, Iran operation difficulties while considerably preserving the environment.

Keywords Controlled release fertilizer · Fluidized-bed coating $\cdot$ Kraft and sulfite liquor $\cdot$ Modified lignin coated urea
Abbreviations
CRF Controlled-release fertilizers
FTIR Fourier transform infrared
SCU Sulfur coated urea
SEM Scanning electron microscopy

\section{Introduction}

The fertilizer industry faces a permanent challenge to improve the efficiency of its products. An ideal fertilizer should have at least three characteristics, including the needs for single application throughout the entire growing season; a high rate of return to the production input; and minimum detrimental effects on soil, water, and atmospheric environments (Shoji and Gandeza 1992; Trenkel 1997). Nitrogen is typically the most important nutrient in crop production in the world and used in the greatest amounts. Among the nitrogen fertilizers, the most widely used one is urea because of its high nitrogen content. Unfortunately, due to its high water-solubility, it leads to ground water contamination particularly by nitrates through leaching processes. In addition, its rapid hydrolysis in soils results in a great quantity of nitrogen (30-50\%) running off and only a fraction is really absorbed by plants (Salman 1988; Malhi et al. 2001; Devassine et al. 2002; Ni et al. 2009; Da Rosa and dos Santos Rocha 2010). One possible way to reduce nitrogen losses and environmental 
pollution involves the use of controlled release urea in which a physical barrier is used to reduce its dissolution rate (Shavit et al. 2003). Controlled release urea is commonly prepared by coating of granular urea with low permeability hydrophobic material. Suitable coating must have four properties, including low prices, being biodegradable, non-toxicity, and high availability. It could effectively resolve and improve nutrient efficiency while reducing the environmental hazards (Shavit et al. 1997; Tomaszewska et al. 2002). Many materials have been reported to be used as coatings, such as sulfur, polyethylene, polysulfone, polyvinyl chloride, polystyrene, polyacrylic acid latex, chitosan, starch, polyvinyl alcohol, mixture of gypsum, limestone, cement, sulfur, and zeolite (Blouin et al. 1971; Salman 1989; Al-Zahrani 2000; Hanafi et al. 2000; Jarosiewicz and Tomaszewska 2003; Liang and Liu 2006; Lan et al. 2011; Mohd Ibrahim et al. 2014; Eghbali Babadi et al. 2015). The sulfur layer is friable and many works have reported the improvement of the coating quality using costly sealants and conditioners (Cole and Simmons 1992; Choi and Meisen 1997; Liu et al. 2008). Some of polymeric materials are non-biodegradable, toxic to the plants, and change the soil's $\mathrm{pH}$, which is undesirable (Azeem et al. 2014). Recently, the development of bio-composite-based coating materials obtained from renewable sources has been investigated to obviate the disadvantages of non-biodegradability of certain polymer coatings and to offset higher operational costs (Calabria et al. 2012).

Lignin is a complex chemical compound and the only aromatic polymer present in wood and it is one of the most abundant biopolymers in nature (Glennie and McCarthy 1962). It is an amorphous polymer with a chemical structure that distinctly differs from the other macromolecular constituents of wood. Its chemical structure contains phenyl propane units, originating from three aromatic alcohol precursors (monolignols), p-coumaryl, coniferyl, and sinapyl alcohols (Dorrestijn et al. 2000; Boerjan et al. 2003). During the chemical pulping processes (Kraft, Soda and Sulphite), the partially degraded lignin is dissolved in the black liquor, from which it can be later isolated by different methods. Moreover, the molecular structure and function groups differ for the various types of lignin (Laurichesse and Avérous 2014). Lignin is a waste material that may be ideal for application to soil and is one of the most slowly decomposing components of dead vegetation, contributing a major fraction of the material that becomes humus as it decomposes. The resulting soil humus, in general, increases the photosynthetic productivity of plant. Moreover, this waste product, when embodied into soil, reduces the nitrification rate of urea (Stevenson 1982; Flaig 1984). Several systems, including urea and lignin, that used matrix method have been described for the formulation of slow release and decrease the solubility of urea. In one of these, urea was entrapped in a lignosulfonate-acrylonitrile graft copolymer matrix (Detroit 1988). Combinations of lignin and ethyl-cellulose were described as controlled release formulations of urea (Fernández-Pérez et al. 2008). The lignosulfonates, Kraft, and Soda lignins were used as coating material for production of coating urea. The nitrogen release through these coatings was measured and compared with uncoated urea granules. To reduce nitrogen release, hydrophobic compounds and crosslinkers were added to the soda flax lignin dispersions. However, complete release of nitrogen still occurred within $1 \mathrm{~h}$ (Mulder et al. 2011).

The objective of this work was to develop an economically feasible and biodegradable layer as coating material for urea fertilizer. For this purpose, lignin obtained from Kraft and Sulfite black liquor of pulp and paper industries was selected as raw material. The lignin with interesting functional properties was extracted and acetylated by acetic acid, and then served as coating layer.

\section{Materials and methods}

To improve the hydrophobicity property, acetylation reaction with acetic acid was used to modify sulfate and sulfite lignin. This approach is an environmentally friendly and cost-effective process with the advantages of using wastewater of pulp and paper mills. Figure 1 shows a schematic description of the experimental procedure.

\section{Material}

Black liquors from Kraft pulping of spruce (Choka Company. Anzali/Iran) and Sulfite process (Chokam Company, Mazandaran/Iran) were used as sources of sulfate and sulfite lignins, respectively. The granular urea was obtained from the Kermanshah Petrochemical Industries Company (Iran) which has a nitrogen content of $46.6 \%$ and a particle size range of $2-4 \mathrm{~mm}$ (Table 1). Aqueous solution of acetic acid (5\%) containing sodium metabisulfite $(0.2 \%)$ was used as acetylating agents. Dichloromethane and ethanol (96\%) were used as the solvents for coating solution preparation. All chemicals were analytical grade (Merck; Germany) and used without further purification.

\section{Methods}

\section{Extraction and chemical modification of lignin}

Ultra-filtration of black liquor for the extraction of lignin has been studied in several previous investigations (Wallberg et al. 2003; Wallberg and Jönsson 2003; Holmqvist 
Fig. 1 Schematic description of the lignin modification and coating procedure

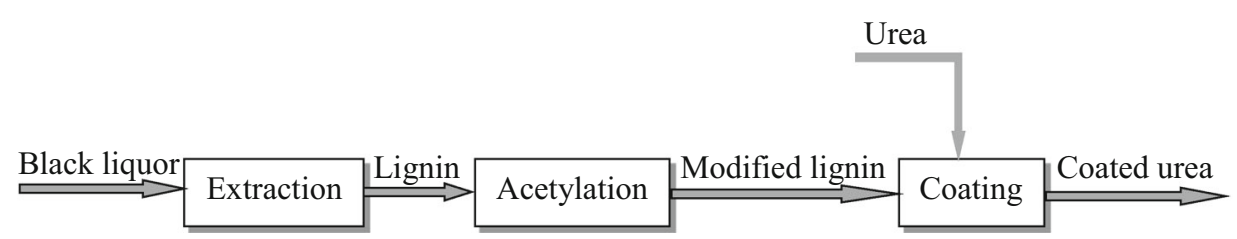

Table 1 Characterizations of raw materials used for preparation of controlled release urea

\begin{tabular}{lll}
\hline Materials & Amount & Unit \\
\hline Urea granules & & \\
Nitrogen content & 46.6 & $\mathrm{wt} \%$ \\
Moisture content & 0.3 & $\mathrm{wt} \%$ \\
Average diameter of the granules & 3.0 & $\mathrm{~mm}$ \\
Molecular weight & 50.6 & $\mathrm{~g} / \mathrm{gmol}$ \\
Density & 750 & $\mathrm{~kg} / \mathrm{m}^{3}$ \\
Melting temperature & 135 & ${ }^{\circ} \mathrm{C}$ \\
Black liquor from Kraft pulping & & \\
Lignin & 43 & $\mathrm{wt} \%$ \\
Hydroxy acid & 20 & $\mathrm{wt} \%$ \\
Sodium & 18 & $\mathrm{wt} \%$ \\
Resin and fatty acids & 6 & $\mathrm{wt} \%$ \\
Acetic acid & 6 & $\mathrm{wt} \%$ \\
Formic acid & 2 & $\mathrm{wt} \%$ \\
Hemicellulose and sugar & 1 & $\mathrm{wt} \%$ \\
Other components & 12 & $\mathrm{wt} \%$ \\
Black liquor from sulfite pulping & & $\mathrm{wt} \%$ \\
Lignin & 16 & $\mathrm{wt} \%$ \\
Hydroxy acid & 24 & $\mathrm{wt} \%$ \\
Sodium & 21 & $\mathrm{wt} \%$ \\
Resin and fatty acids & 5 & $\mathrm{wt} \%$ \\
Acetic acid & 11 & \\
Formic acid & 2 & $\mathrm{wt} \%$ \\
Hemicellulose and sugar & 19 & \\
Other components & & \\
\hline
\end{tabular}

et al. 2005; Wallberg et al. 2006). The lignin was extracted with a polymeric membrane, i.e., polyethersulfones $(18 \%)$ containing polyvinyl pyrrolidone $(1 \%)$ in a laboratory unit equipped with dead-end cell. Then, the extracted lignin was acetylated with acetic acid to block hydrophilic groups and improve coating properties, i.e., water sensitivity and hydrophobicity. Required amount of extracted lignin was acetylated under desired conditions, as shown in Table 2. The precipitated modified lignin was washed with $1 \mathrm{~L}$ deionized water and dried at $35-40{ }^{\circ} \mathrm{C}$ in an oven. The modified lignin was characterized through FTIR spectroscopy.

\section{Coating of granular urea}

Controlled release urea is commonly produced by the pan, rotary drum, and fluidized-bed coating techniques. The fluidized-bed process results in coatings of good quality and of uniform thickness (Tzika et al. 2003). Experimental setup, including the fluidized-bed coater and its accessories, is shown in Fig. 2. The fluidized bed was made of Pyrex column (20 cm in diameter and $40 \mathrm{~cm}$ in height). In each experimental run, granular urea $(250 \mathrm{~g})$ was loaded into fluidized-bed coater. The blower and pre-heater were run for 5-10 min to achieve a steady-state fluidization condition. Preliminary experiments were conducted before obtaining the optimum process variable of fluidization. The coating solution was prepared by dissolution of the extracted lignin or modified lignin powder in adequate solvent and sprayed into the granular urea via a nozzle. Deionized water was used as a solvent of extracted Kraft and Sulfite lignin, and a mixture of ethanol/dichloromethane was used as the solvent of modified lignin with acetic acid. Operating parameters of coating experiments are shown in Table 3. Spraying step was completed when a film of specified thickness was formed and the thickness of coated layer was controlled by regulating the coating period and coating solution flow rate. The coated granules were dried in the same apparatus at $70{ }^{\circ} \mathrm{C}$ for additional 10 min where after the granules were taken out for analysis. To prepare the sulfur coated urea, the sulfur was melted before being sprayed. Percentage of coating was determined as the weight of the modified lignin in the coating solution divided by the final weight of the product.

\section{Characterization}

The extracted lignin and modified lignins were characterized using Fourier Transform Infrared Spectroscopy (Bomem MB 155S series FTIR spectrophotometer;

Table 2 Experimental conditions of acetylation reaction of lignin

\begin{tabular}{llllll}
\hline Reagent & Reactor & Time & Temperature & Centrifuging & Product \\
\hline Acetic acid/sodium metabisulfite & Two necked flask with a condenser & $18 \mathrm{~h}$ & $80{ }^{\circ} \mathrm{C}$ & Four times, 60 min, $4000 \mathrm{rpm}$ & Brown powder \\
\hline
\end{tabular}


Fig. 2 Experimental setup, including fluidized-bed apparatus

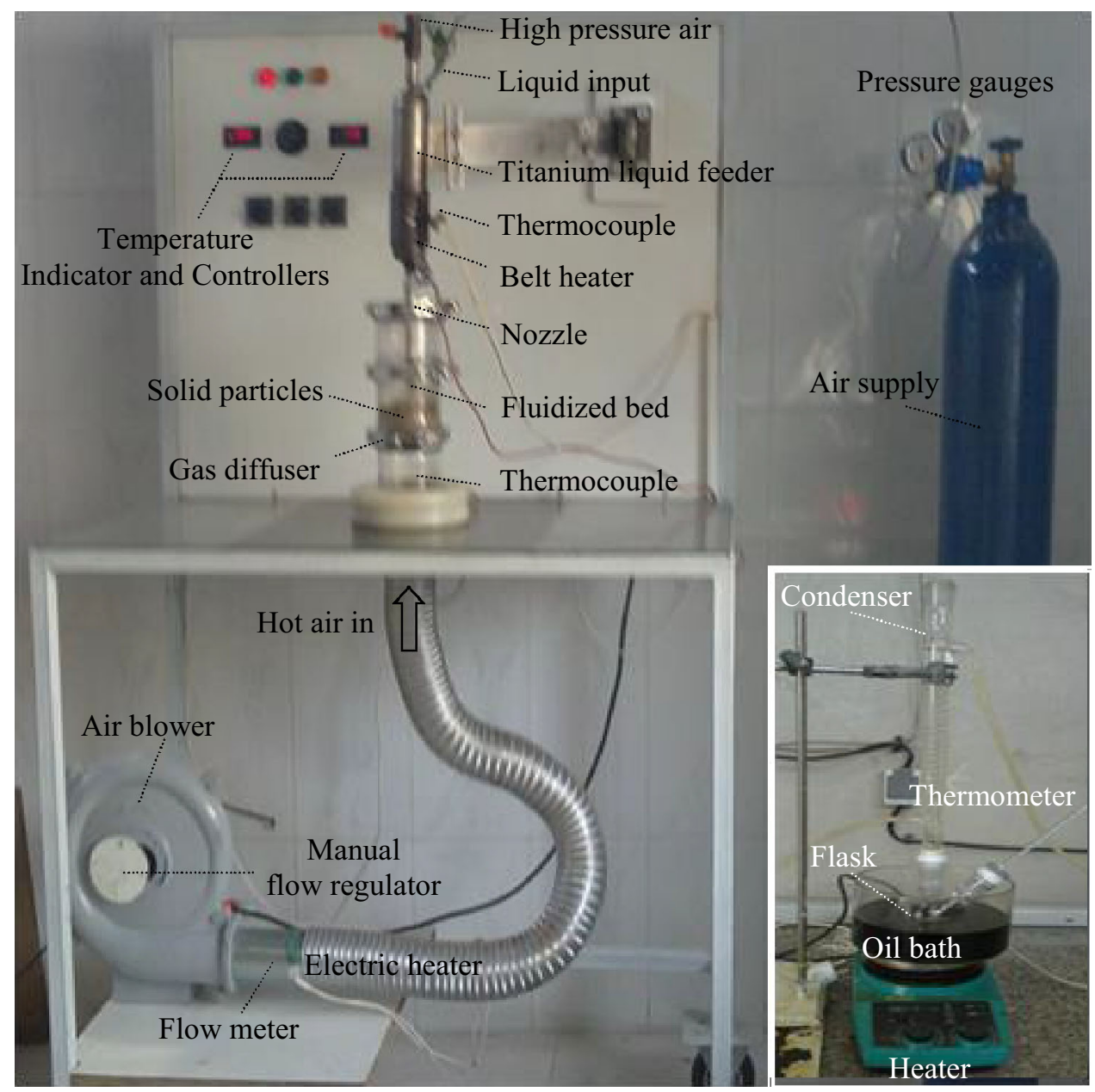

Table 3 Operating parameters of coating process in a fluidized bed

\begin{tabular}{llll}
\hline Process variable & \multicolumn{2}{l}{ Coating material } & \\
\cline { 2 - 4 } & Lignin & Modified lignin & Sulfur \\
\hline Weight of urea $(\mathrm{g})$ & 250 & 250 & 250 \\
Air temperature $\left({ }^{\circ} \mathrm{C}\right)$ & $80-85$ & $70-80$ & $70-80$ \\
Air flow rate $\left(\mathrm{cm}^{3} / \mathrm{min}\right)$ & $35-45$ & $35-45$ & $35-45$ \\
Coating solution temperature $\left({ }^{\circ} \mathrm{C}\right)$ & $90-100$ & $40-50$ & $120-125$ \\
Coating solution flow rate $\left(\mathrm{cm}^{3} / \mathrm{min}\right)$ & 15 & 20 & 10 \\
Coating solution pressure $(\mathrm{bar})$ & $15-18$ & $15-18$ & $15-18$ \\
\hline
\end{tabular}

Switzerland). Surface morphology of granular urea and modified lignin coated urea was analyzed by scanning electron microscopy (SEM) and petrographic microscopy (Leica 200M, USA). SEM images were obtained at the required magnification at room temperature.

\section{Nitrogen release test}

To measure the amount of nitrogen release in soil, synthesized fertilizer ( $3 \mathrm{~g}$ ) was added to pot containing $900 \mathrm{~g}$ of soil, mixed, and kept at the room temperature of $25 \pm 5{ }^{\circ} \mathrm{C}$ for 2 months. The humidity of pot's soil was controlled around field capacity by weighting method. Soil samples were collected from three different points in a 2 day interval by a narrow glass pipe with a diameter of $4 \mathrm{~mm}$ and height of $30 \mathrm{~cm}$ and subjected to nitrogen release test. The sampling points were isolated by the small-opening grid in the way that the samples only contained soil and none of synthesized slow release fertilizer beads. 


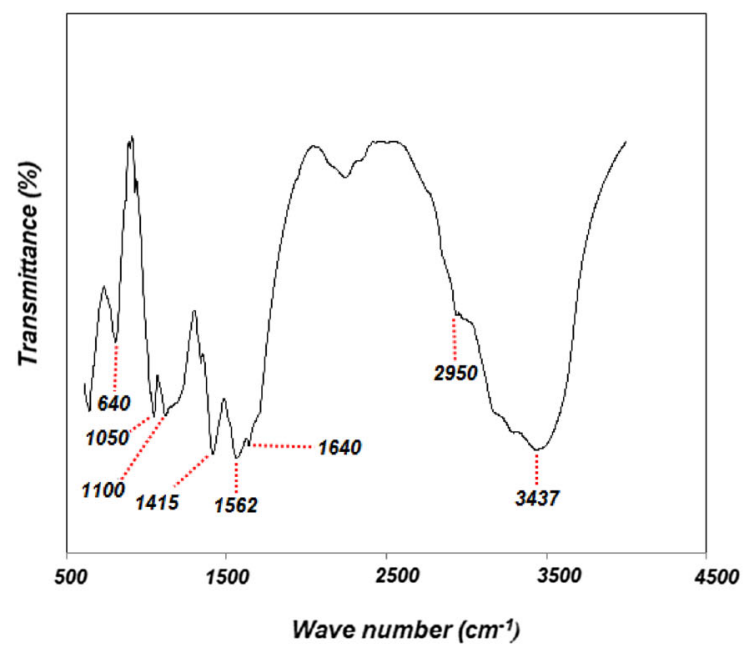

(a) Sulfite lignin

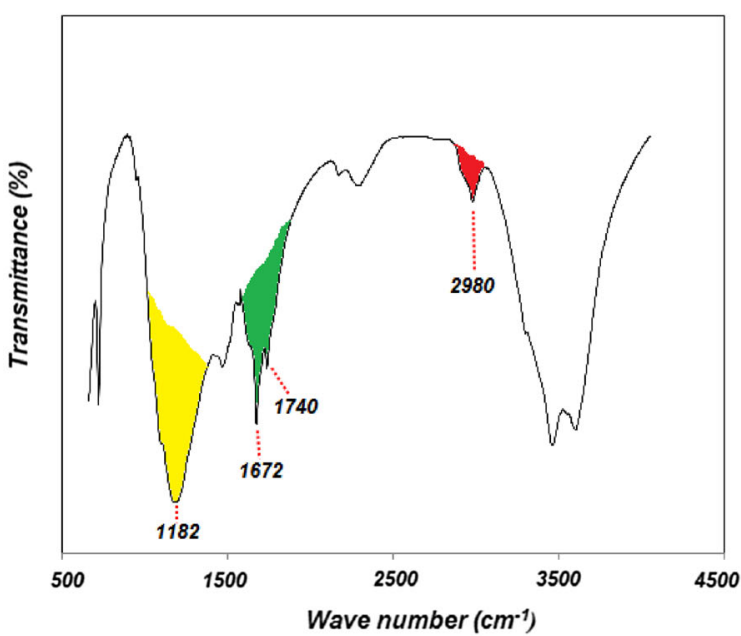

(c) Acetylated Sulfite lignin

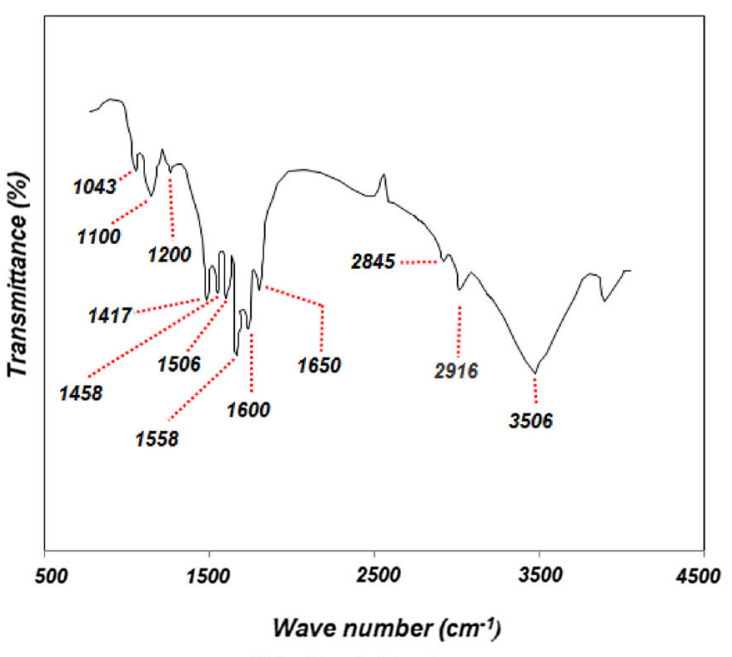

(b) Kraft lignin

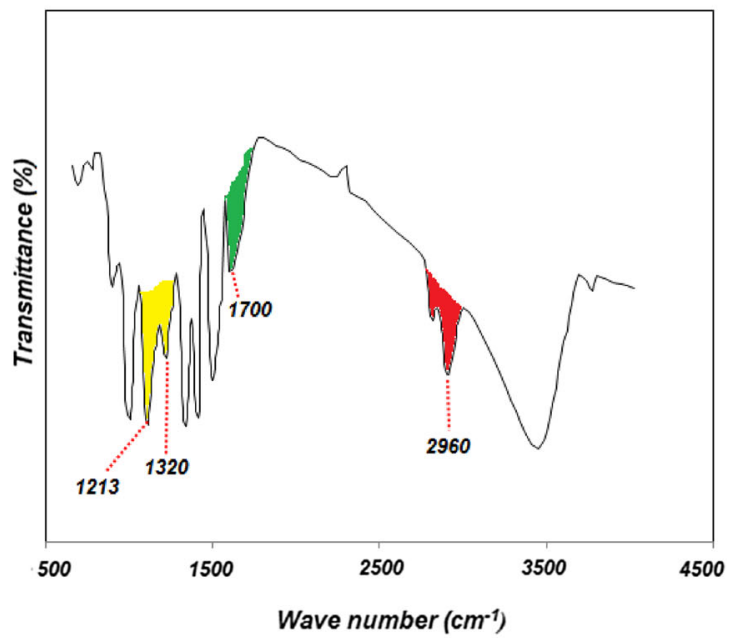

(d) Acetylated Kraft lignin

To measure the nitrogen release from fertilizer, a mass of $10 \mathrm{~g}$ coated urea was poured in deionized water $(200 \mathrm{ml})$. Samples $(10 \mathrm{ml})$ were withdrawn during intervals and subjected to the Kjeldahl method concluding the amount of nitrogen released from the fertilizer.

\section{Results and discussion}

Lignin macromolecule contains various functional groups, such as methoxyl, hydroxyl, and benzyl alcohol groups, and few terminal aldehyde groups (Nikitin 1961). The hydroxyl functional groups, mainly phenolic and alcoholic hydroxyl groups, may result in an increase hydrophilicity of lignin.

FTIR spectra of unmodified lignin extracted from black liquor and modified lignin are shown in Fig. 3. Some sodium hydroxide $(0.05 \mathrm{~N})$. 
Fig. 4 Mechanism of the acetylation reaction with acetic acid/sodium metabisulfite. a Phenolic groups; b alcoholic groups

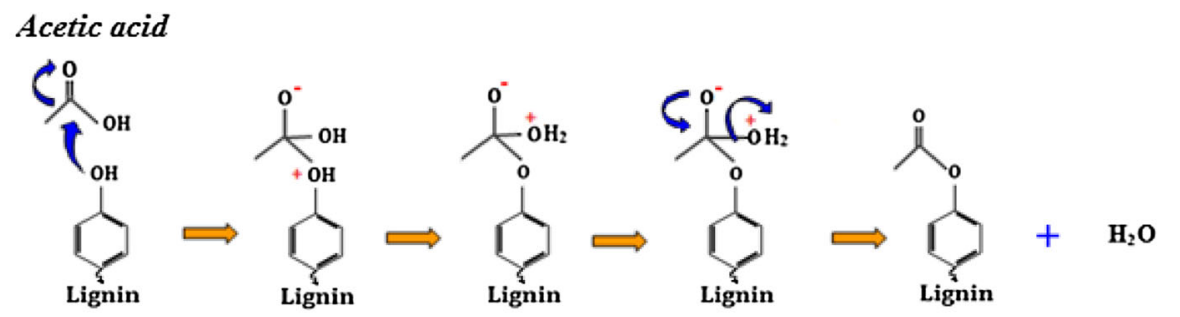

(a) Phenolic groups

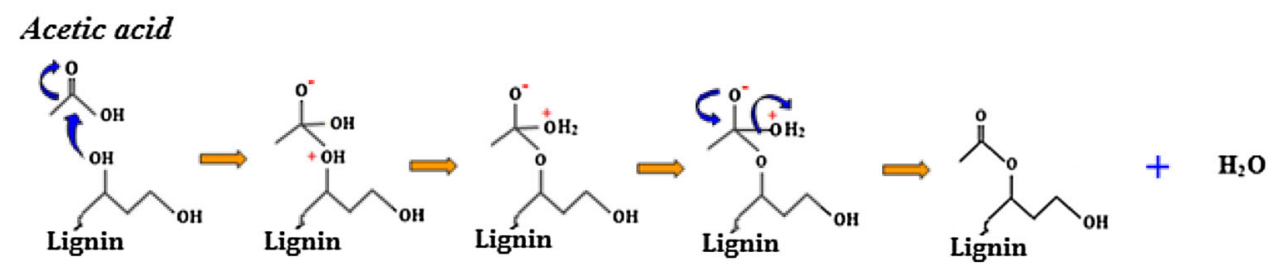

(b) Alcoholic groups

characteristic peaks in lignin spectrum can be ascribed as follows: The distinct band appearing at $640 \mathrm{~cm}^{-1}$ in the spectra of sulfite lignin (Fig. 3 a) was assigned to the sulphonic groups formed from the reaction of sodium sulphite with the secondary $\mathrm{OH}$ of the aliphatic side chain of lignin which is not the case in Kraft lignin spectrum. The bond at $1043-1200 \mathrm{~cm}^{-1}$ might be caused by vibration of $\mathrm{C}-\mathrm{O}$ bonds in phenolic, alcoholic groups, and by vibration of $\mathrm{C}-$ $\mathrm{O}-\mathrm{C}$ in ethers groups. The absorption bonds around 1050 and $1100 \mathrm{~cm}^{-1}$ are referred to primary and secondary alcoholic groups, respectively. The peaks at 1562 and $1640 \mathrm{~cm}^{-1}$ are related to the aromatic structural vibrations. The bond at $1650 \mathrm{~cm}^{-1}$ is due to stretching vibration of $\mathrm{C}=\mathrm{C}$ in alkenes groups. The absorption bonds located in 2916 and $2845 \mathrm{~cm}^{-1}$ wave numbers are caused by C-H stretching vibration of the methoxyl groups. The strong wide absorption bond between 3100 and $3500 \mathrm{~cm}^{-1}$ is ascribed to $\mathrm{OH}$ stretching vibration, which indicates the presence of alcoholic and phenolic hydroxyl groups involved in hydrogen bonds. The result of FTIR spectra confirmed that the precipitated material is extracted lignin which was hydrophilic because of existence many hydroxyl groups in its structure. Lower absorption intensity was observed for Kraft Lignin than for Sulfite lignin which is attributed to the high oxidation and degradation power during the two pulping processes (Fig. 3a, b).

The FTIR spectra of extracted lignin and modified lignin (Fig. 3c, d) show structural differences between them. The acetylation reaction has changed the structure of lignin when the main absorption bands $(\mathrm{C}=\mathrm{O})$ of acetyl groups have been appeared distinctly at $1700-1750 \mathrm{~cm}^{-1}$ that related to carboxylic acid group that formed by substitution of hydrogen atoms of the hydroxyl groups by acetyl groups. The new bond at 1195,1213 , and $1320 \mathrm{~cm}^{-1}$ in FTIR spectra of acetylated lignin is characteristic of $\mathrm{C}-\mathrm{O}$ stretching vibration of esters and acidic groups. Meanwhile, the peak at $3100-3500 \mathrm{~cm}^{-1}$ of absorption is weakened after acetylation. Therefore, it can be concluded that hydroxyl groups in lignin were acetylated and replaced by acetyl groups. The absorption at $2934 \mathrm{~cm}^{-1}$, predominantly, is due to $\mathrm{C}-\mathrm{H}$ stretching in aromatic methoxyl groups. Increase of this peak intensity after modification by acetic acid is probably due to addition of methyl and methylene groups to side chains of acetylated lignin.

Figure 4 shows the proposed mechanism of acetylation reaction with acetic acid/sodium metabisulfite. A reaction involving the replacement of the hydrogen atom of a hydroxyl group with an acetyl group $\left(\mathrm{CH}_{3} \mathrm{CO}\right)$ yields a specific ester. Acetylation of the lignin leads to a partial or full $\mathrm{OH}$ bond loss, since $\mathrm{OH}$ groups were replaced by ester groups $\left(\mathrm{CH}_{3} \mathrm{COO}\right)$.

Figure $5 \mathrm{a}, \mathrm{b}$ presents graphs and micrographs of the surface of uncoated urea and lignin coated urea $(10 \%$ coating) obtained by petrographic microscope and SEM. Lignin coated urea did not show a smooth surface, containing irregularities. In addition, crystal structure was observed on the particle surfaces of lignin coated urea. The formation of this crystal structure can be ascribed to phenolate salt crystal. Figure $5 \mathrm{c}$ shows the geological images (left) of acetylated lignins and SEM images (right) of urea coated with various percentage of acetylated Kraft lignin layer. Pinholes were clearly seen in samples with $5.0 \%$ coating. These relatively large pinholes are the principal path for the water diffusion into coated granule and nitrogen 

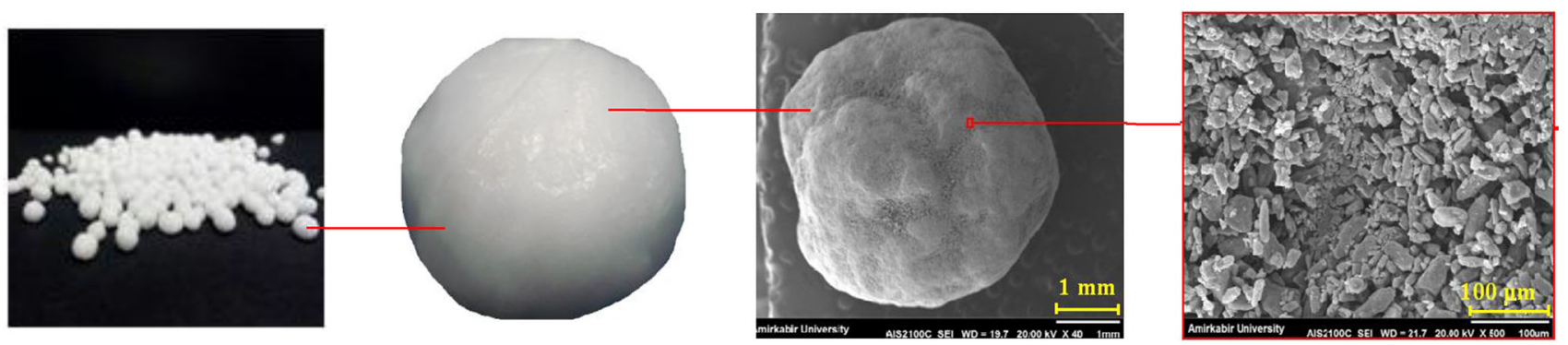

(a) Uncoated urea granule
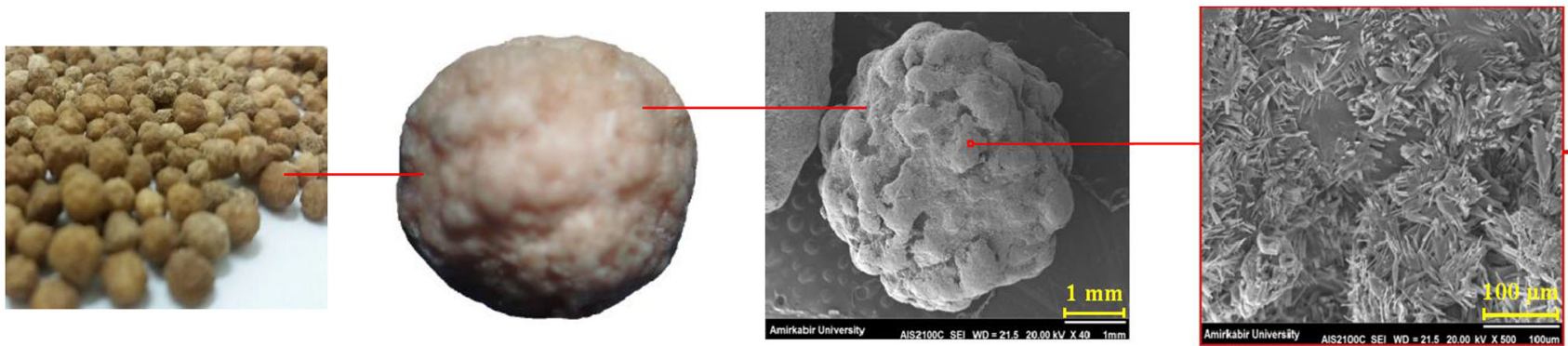

(b) Lignin coated urea

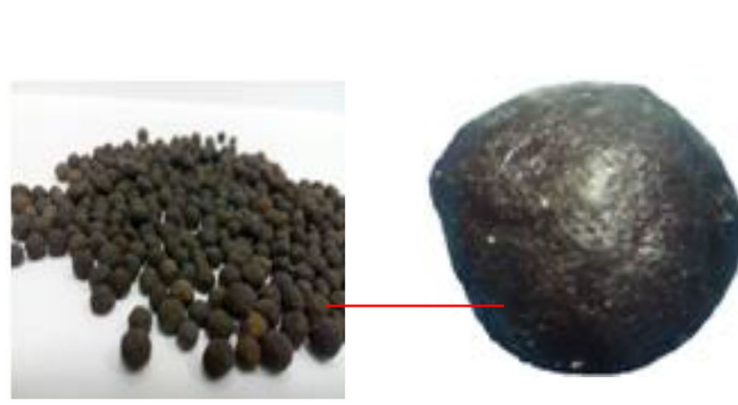

Acetylated Sulfite lignin

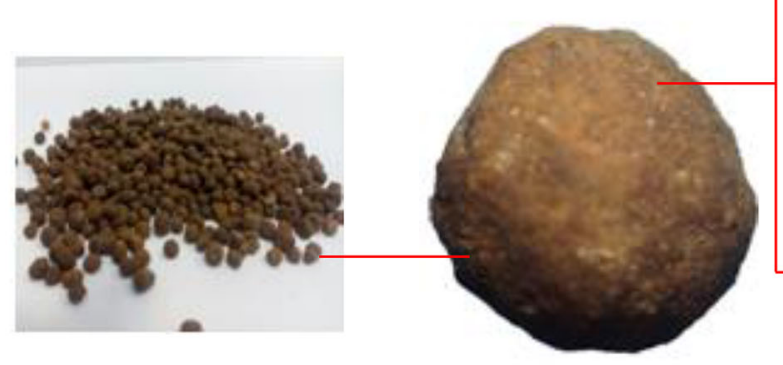

Acetylated Kraft lignin
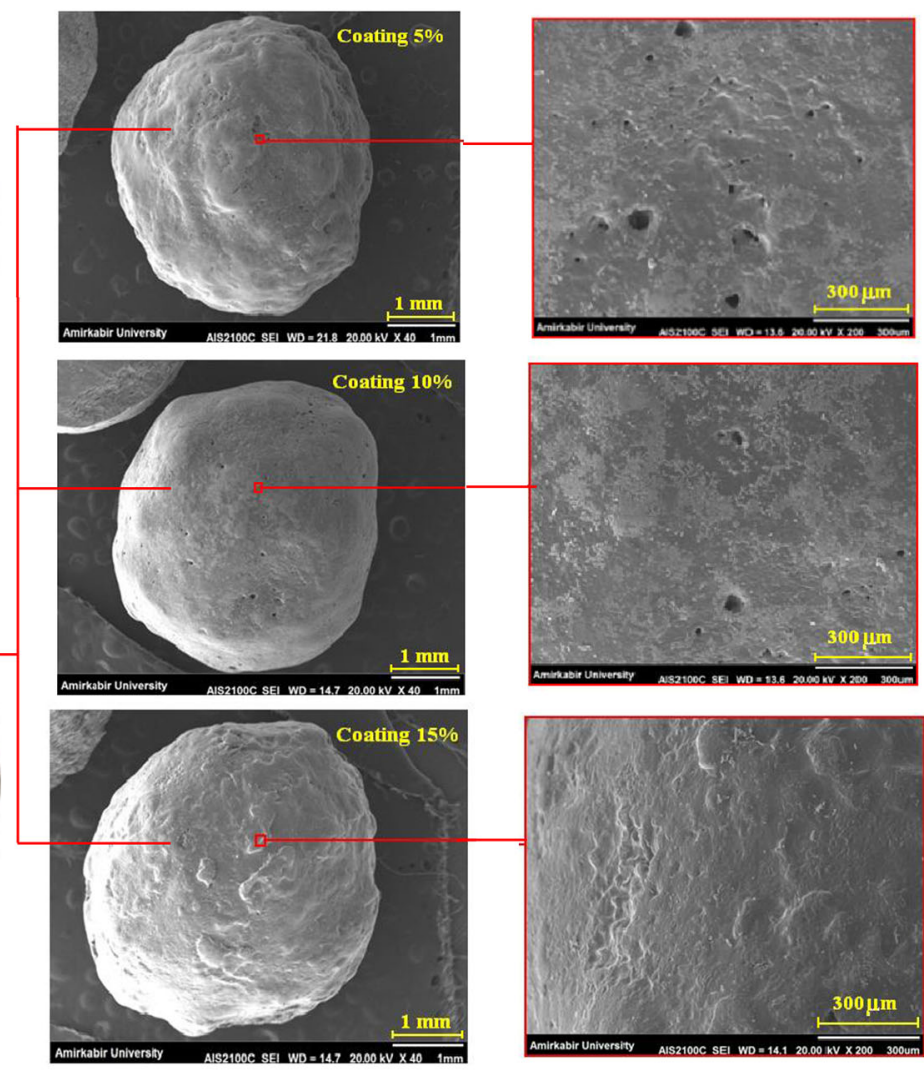

(c) Acetylated lignin coated urea

Fig. 5 Petrographic microscope and SEM images of urea, urea coated with lignin, and modified lignin with acetic acid. a Uncoated urea granule, b lignin coated urea, and c acetylated lignin coated urea

release. Nutrients become available when the coating degrades to expose them or when nutrients diffuse through small pores in the coating. Particles with thin or imperfect spots in the coating are covered by the sealant to moderate the release rate. The surface of the coated urea became more uniform and the pores sizes became smaller as the coating 
percentage increased. Although the surface of the urea coated with $15.0 \%$ coating was not perfectly uniform and smooth, it is quite free from visible defects like cracks and pinholes. The longest delay in release comes from the thicker coated particles with no imperfections. Thus, it is the variability in the particles that provides the sustained release of nutrients from coated urea.

Complete release of urea coated with Kraft and Sulfite lignin still occurred within $1 \mathrm{~h}$ in water. This can be explained by partly dissolution of urea in the aqueous lignin layer during coating process. The reaction of urea with phenolic hydroxyl groups of lignin results in the formation of phenolate salt in the coating layer; therefore, the coating layer has a low resistance to water diffusion.

Release of nitrogen is governed by the thickness of coating and imperfections in coating surface. Figure 6 shows nitrogen release rate of coated urea with modified lignin for three different coating percentages and in water medium. The release rate could be controlled by varying the total amount of coating layer. The dissolution rate decreases with the increase in coating percentage. For coated urea with acetylated Kraft lignin and Sulfite lignin, the dissolution rate of 88 and $97 \%$ was obtained after $24 \mathrm{~h}$ for the sample with $5.0 \%$ coating, respectively, whereas the corresponding value was 43 and $72 \%$ for the sample with $15.0 \%$ coating. This fact is associated with the reduction in the number of pinholes which are the primary path for nitrogen release from coated urea. It is important to note that higher the percentage content of coated layer results in lower release of nitrogen. For all experimental range, the nitrogen release for urea coated with acetylated Sulfite lignin was more than that of urea coated with acetylated Kraft lignin.

To achieve more practical results, the release rate of nitrogen was investigated in soil collected from agricultural farm in Kermanshah province/Iran (Fig. 7). The release rate of nitrogen was more slowly in soil than in water. However, the same trend was observed for acetylated Sulfite and Kraft lignin. Some of the physical and chemical properties of the soil are shown in Table 4.

To compare the quality of synthesized fertilizer with available commercial one, an experimental run was
Fig. 6 Release rate of urea coated with acetylated lignin in water. a Sulfite lignin; b Kraft lignin

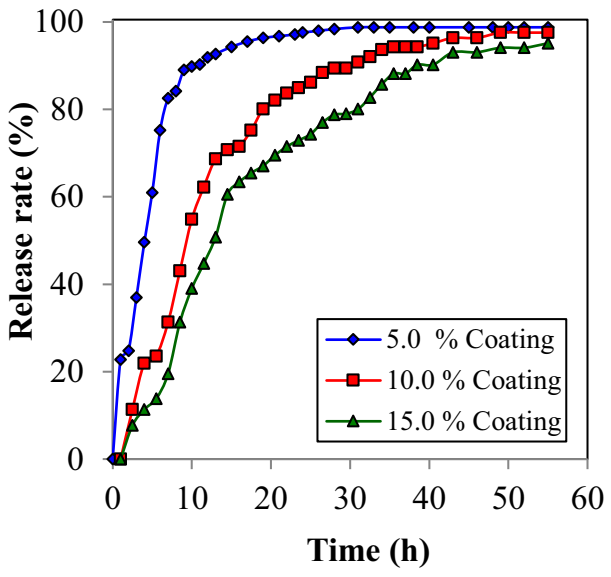

(a) Sulfite lignin

Fig. 7 Release rate of urea coated with acetylated lignin in soil. a Sulfite lignin; b Kraft lignin

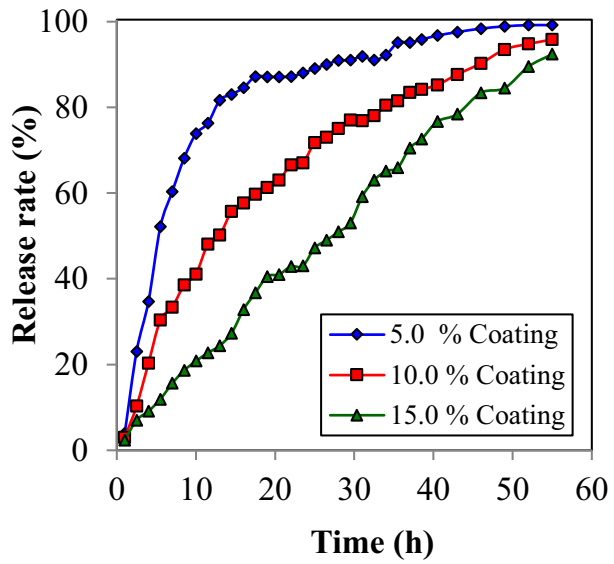

(b) Kraft lignin

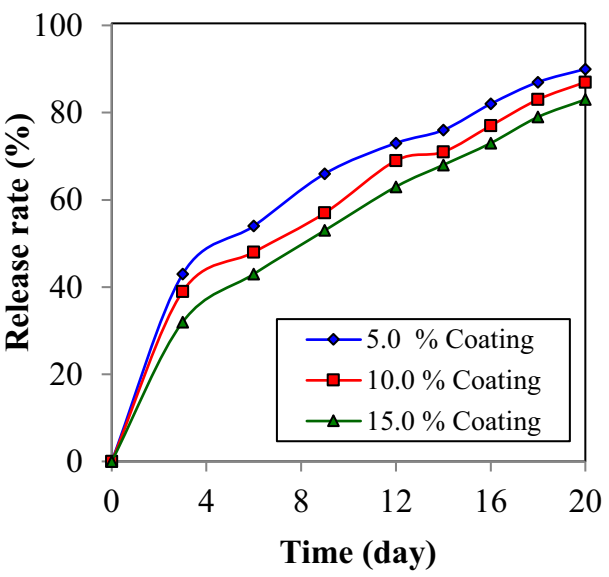

(a) Sulfite lignin

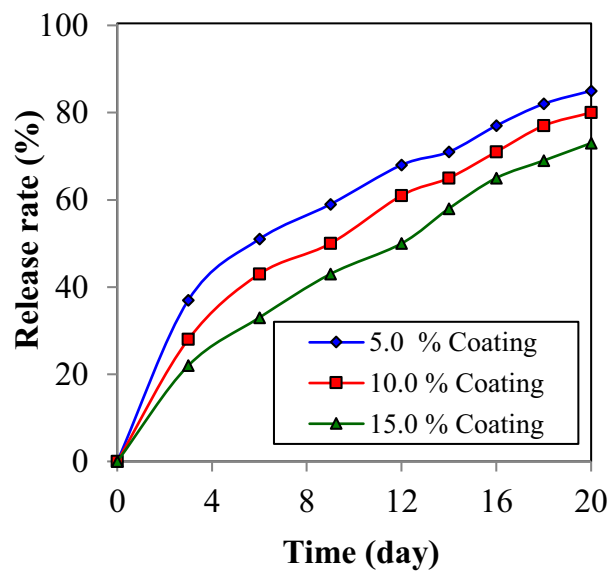

(b) Kraft lignin 
Table 4 Properties of soil used for release rate of coated urea

\begin{tabular}{ll}
\hline Parameter & Value \\
\hline pH & 7.20 \\
Electrical conductivity (ds/m) & 0.40 \\
Organic materials (\%) & 2.11 \\
Nitrogen (\%) & 0.24 \\
Calcium carbonate equivalent (\%) & 9.35 \\
Silt (\%) & 55.17 \\
Sand (\%) & 19.27 \\
Clay (\%) & 25.56 \\
Texture & Silt loam \\
\hline
\end{tabular}

conducted with sulfur coated urea (SCU) synthesized in our laboratory. Figure 8 illustrates the nitrogen release rate for SCU (without using conditioner and sealant) and urea coated by modified lignin for three different coating percentages. After 7 days, the nitrogen release of SCU in soil was more than urea coated with acetylated lignin. The nitrogen content of SCU has been released almost completely, after 11 days, whereas this value was $70 \%$ (after 18 days) for the urea coated with acetylated Kraft lignin. This is probably due to complete coating of urea by acetylated lignin that prolonged the release time of nitrogen. The sulfur coating process is highly temperature dependent. A small change in coating temperature changes the morphology of sulfur. The sulfur cannot create a perfect-uniform coating on the surface of urea and some crack might be observed on the surface, which makes nitrogen release un-controllable. Moreover, some regions of the coating are thick and some regions are thin. The thinner part is easily broken and increases water penetration into granules that cause rapid dissolution of nitrogen.

For the application as a controlled release coating, the water resistance is an important feature. The dissolution rate of nitrogen reduced significantly for urea coated with modified lignin. Probably, acetylation increases the hydrophobicity and thereby reduces the water-sensitivity of lignin coating which results in a decrease of nitrogen release. In this coating layer, only some parts of the alcoholic and phenolic groups were acetylated and the others remained non-acetylated. Acetylated groups are characterized by hydrophobicity, while non-acetylated groups have the ability to establish hydrogen bonds with the coating surface, and thus, it can enhance the surface adhesion. FTIR spectra showed that Sulfite lignin is more hydrophilic than Kraft lignin. Due to its hydrophobic nature and adhesion to the surface, Kraft lignin modified with acetic acid/sodium metabisulfite showed the high performance as coating material (Fig. 9). Besides the hydrophobicity, the coating quality has the major influence on the release of urea. The fluidization is a suitable technique to produce a quality product with the uniform coating layer.

\section{Conclusions}

Extracted lignin from Kraft and Sulfite black liquor has the potential to be developed as a coating layer. Urea has been successfully coated with modified lignin to obtain granular coated urea. The key findings of this work are:
Fig. 8 Release rate of coated urea in soil after 7 days

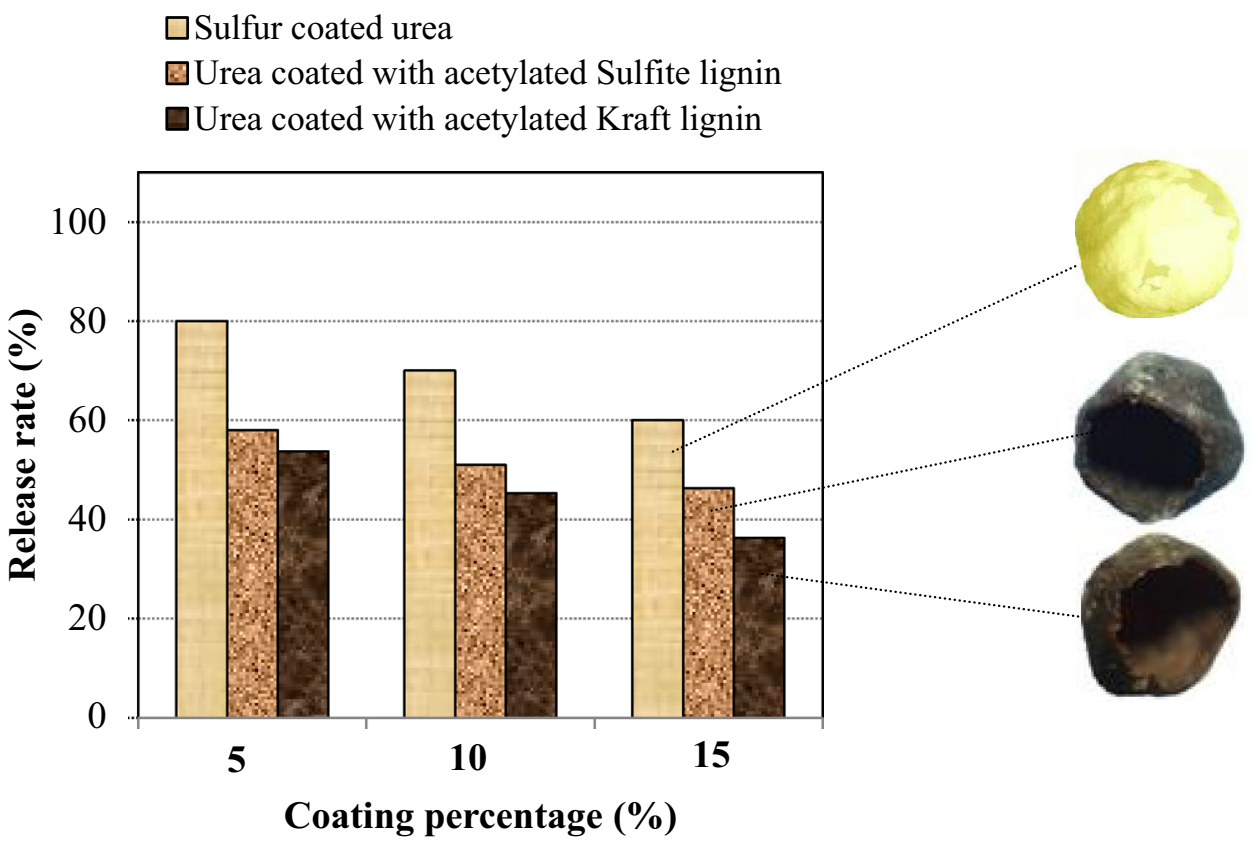

Springer 


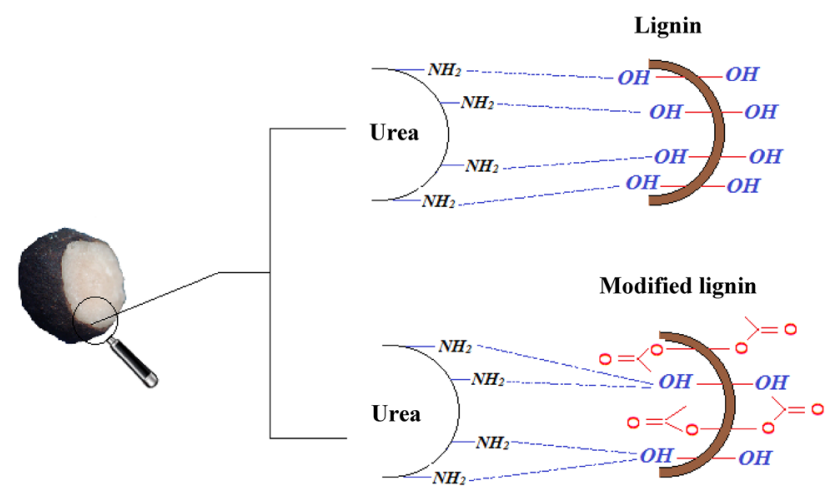

Fig. 9 Interface phenomenon between urea and coating agent

- The hydrophobic and adhesion surface characters of the coating material are two important factors affecting the quality of the coating and have a substantial influence on the nitrogen release. The hydrophobicity property of lignin layer was improved by its modification through acetylation reaction with acetic acid. The phenolic and alcoholic $\mathrm{OH}$ groups, which can be able to form hydrogen bond and increase its hydrophilic property, are converted to ester groups. However, adhesion surface characters of the coating decreased with an increase in coating hydrophobicity.

- The use of bio-polymeric materials, such as lignin, in controlled release fertilizer, could help to increase the efficiency of delivery of the bioactive material for longer period and prevent pollution of surface and underground water with nitrate.

- The existing environmental problems resulting from effluent of pulp and paper industries could be minimized by investments from both the fertilizer and the pulp/paper industries. This would result in economical and environmental benefits from the raw materials used in fertilizer industry.

Open Access This article is distributed under the terms of the Creative Commons Attribution 4.0 International License (http://crea tivecommons.org/licenses/by/4.0/), which permits unrestricted use, distribution, and reproduction in any medium, provided you give appropriate credit to the original author(s) and the source, provide a link to the Creative Commons license, and indicate if changes were made.

\section{References}

Al-Zahrani SM (2000) Utilization of polyethylene and paraffin waxes as controlled delivery systems for different fertilizers. Ind Eng Chem Res 39:367-371. doi:10.1021/ie980683f

Azeem B, Kushaari K, Man ZB, Basit A, Thanh TH (2014) Review on materials and methods to produce controlled release coated urea fertilizer. J Control Release 181:11-21. doi:10.1016/j. jconrel.2014.02.020
Blouin GM, Rindt DW, Moore OE (1971) Sulfur-coated fertilizer for controlled release: pilot plant production. J Agric Food Chem 19:801-808. doi:10.1021/jf60177a039

Boerjan W, Ralph J, Baucher M (2003) Lignin biosynthesis. Annu Rev Plant Biol 54:519-546. doi:10.1146/annurev

Calabria L, Vieceli N, Bianchi O, Oliveira RVB, Nascimento Filho I, Schmidt V (2012) Soy protein isolate/poly (lactic acid) injectionmolded biodegradable blends for slow release of fertilizers. Ind Crops Prod 36:41-46. doi:10.1016/j.indcrop.2011.08.003

Choi MMS, Meisen A (1997) Sulfur coating of urea in shallow spouted beds. Chem Eng Sci 52:1073-1086. doi:10.1016/S00092509(96)00377-6

Cole RD, Simmons CL (1992) Sulfur coating of urea containing gelling clays. US Patent, 4,885,021

Da Rosa GS, dos Santos Rocha SC (2010) Effect of process conditions on particle growth for spouted bed coating of urea. Chem Eng Process Process Intensif 49:836-842. doi:10.1016/j. cep.2010.06.005

Detroit WJ (1988) Controlled release formulation for fertilizers. US Patent, 4,789,391

Devassine M, Henry F, Guerin P, Briand X (2002) Coating of fertilizers by degradable polymers. Int J Pharm 242:399-404. doi:10.1016/S0378-5173(02)00225-9

Dorrestijn E, Laarhoven LJJ, Arends IWCE, Mulder P (2000) The occurrence and reactivity of phenoxyl linkages in lignin and low rank coal. J Anal Appl Pyrolysis 54:153-192. doi:10.1016/ s0165-2370(99)00082-0

Eghbali Babadi F, Yunus R, Abdul Rashid S, Mohd Salleh MA, Ali S (2015) New coating formulation for the slow release of urea using a mixture of gypsum and dolomitic limestone. Particuology 23:62-67. doi:10.1016/j.partic.2014.12.011

Fernández-Pérez M, Garrido-Herrera FJ, González-Pradas E, Villafranca-Sanchez M, Flores-Céspedes F (2008) Lignin and ethylcellulose as polymers in controlled release formulations of urea. J Appl Polym Sci 108:3796-3803. doi:10.1002/app.27987

Flaig W (1984) Soil organic matter as a source of nutrients. In: Organic matter and rice, International Rice Research Institute, Philippines, pp 73-91

Glennie DW, McCarthy JL (1962) Pulp and paper science and technology. McGraw-Hill Book Company, New York

Hanafi MM, Eltaib SM, Ahmad MB (2000) Physical and chemical characteristics of controlled release compound fertilizer. Eur Polym J 36:2081-2088. doi:10.1016/S0014-3057(00)00004-5

Holmqvist A, Wallberg O, Jönsson AS (2005) Ultrafiltration of Kraft black liquor from two Swedish pulp mills. Chem Eng Res Des 83:994-999. doi:10.1205/cherd.04204

James CS (1995) Analitical chemistry of foods. Blackie Academic Professional Press. J AOAC Int 23:899-921

Jarosiewicz A, Tomaszewska M (2003) Controlled-release NPK fertilizer encapsulated by polymeric membranes. J Agric Food Chem 51:413-417. doi:10.1021/jf020800o

Lan R, Liu Y, Wang G, Wang T, Kan C, Jin Y (2011) Experimental modeling of polymer latex spray coating for producing controlled release urea. Particuology 9:510-516. doi:10.1016/j. partic.2011.01.004

Laurichesse S, Avérous L (2014) Chemical modification of lignin: towards biobased polymers. Prog Polym Sci 39:1266-1290. doi:10.1016/j.progpolymsci.2013.11.004

Liang R, Liu MZ (2006) Preparation and properties of a doublecoated slow-release and water-retention urea fertilizer. J Agric Food Chem 54:1392-1398. doi:10.1021/jf052582f

Liu YH, Wang TJ, Qin L, Jin Y (2008) Urea particle coating for controlled release by using DCPD modified sulfur. Powder Technol 183:88-93. doi:10.1016/j.powtec.2007.11.022

Malhi SS, Grant CA, Johnston AM, Gill KS (2001) Nitrogen fertilization management for no-till cereal production in the 
Canadian Great Plains: a review. Soil Tillage Res 60:101-122. doi:10.1016/S0167-1987(01)00176-3

Mohd Ibrahim KR, Eghbali Babadi F, Yunus R (2014) Comparative performance of different urea coating materials for slow release. Particuology 17:165-172. doi:10.1016/j.partic.2014.03.009

Mulder WJ, Gosselink RJA, Vingerhoeds MH, Harmsen PFH, Eastham D (2011) Lignin based controlled release coatings. Ind Crops Prod 34:915-920. doi:10.1016/j.indcrop.2011.02.011

Ni B, Liu M, Lü S (2009) Multifunctional slow-release urea fertilizer from ethylcellulose and superabsorbent coated formulations. Chem Eng J 155:892-898. doi:10.1016/j.cej.2009.08.025

Nikitin VM (1961) Lignin. Moscow-Leningrad, Goslesbumizdat, p 316

Salman OA (1988) Polymer coating on urea prills to reduce dissolution rate. J Agric Food Chem 36:616-621

Salman OA (1989) Polyethylene-coated urea. 1. Improved storage and handling properties. Ind Eng Chem Res 28:630-632

Shavit U, Shaviv A, Shalit G, Zaslavsky D (1997) Release characteristics of a new controlled release fertilizer. J Control Release 43:131-138. doi:10.1016/S0168-3659(96)01478-2

Shavit U, Reiss M, Shaviv A (2003) Wetting mechanisms of gelbased controlled-release fertilizers. J Control Release 88:71-83. doi:10.1016/s0168-3659(02)00455-8

Shoji S, Gandeza AT (1992) Controlled release fertilizers with polyolefin resin coating. Kanno, Sendai
Stevenson FJ (1982) Humus chemistry. Wiley-Interscience, New York

Tomaszewska M, Jarosiewicz A, Karakulski K (2002) Physical and chemical characteristics of polymer coatings in CRF formulation. Desalination 146:319-323. doi:10.1016/S00119164(02)00501-5

Trenkel ME (1997) Controlled-release and stabilized fertilizers in agriculture. International Fertilizer Industry Association, Paris, pp 8-16

Tzika M, Alexandridou S, Kiparissides C (2003) Evaluation of the morphological and release characteristics of coated fertilizer granules produced in a Wurster fluidized bed. Powder Technol 132:16-24. doi:10.1016/S0032-5910(02)00345-5

Wallberg O, Jönsson AS (2003) Influence of the membrane cut-off during ultrafiltration of kraft black liquor with ceramic membranes. Chem Eng Res Des 81:1379-1384. doi:10.1205/ 026387603771339591

Wallberg O, Jönsson AS, Wimmerstedt R (2003) Ultrafiltration of Kraft black liquor with a ceramic membrane. Desalination 156:145-153. doi:10.1016/S0011-9164(03)00337-0

Wallberg O, Linde M, Jönsson AS (2006) Extraction of lignin and hemicelluloses from Kraft black liquor. Desalination 199:413-414. doi:10.1016/j.desal.2006.03.094 